This item was submitted to Loughborough's Research Repository by the author.

Items in Figshare are protected by copyright, with all rights reserved, unless otherwise indicated.

\title{
A biosynthetically inspired route to substituted furans using the Appel reaction: total synthesis of the furan fatty acid F5
}

PLEASE CITE THE PUBLISHED VERSION

http://dx.doi.org/10.1039/C7CC03229C

\section{PUBLISHER}

(c) Royal Society of Chemistry

\section{VERSION}

AM (Accepted Manuscript)

\section{PUBLISHER STATEMENT}

This work is made available according to the conditions of the Creative Commons Attribution-NonCommercialNoDerivatives 4.0 International (CC BY-NC-ND 4.0) licence. Full details of this licence are available at: https://creativecommons.org/licenses/by-nc-nd/4.0/

\section{LICENCE}

CC BY-NC-ND 4.0

\section{REPOSITORY RECORD}

Lee, Robert, Martin Lindley, Gareth Pritchard, and Marc Kimber. 2017. "A Biosynthetically Inspired Route to Substituted Furans Using the Appel Reaction: Total Synthesis of the Furan Fatty Acid $F_{5}$ ". Loughborough University. https://hdl.handle.net/2134/25266. 


\section{Journal Name}

\section{COMMUNICATION}

\section{A biosynthetically inspired route to substituted furans using the Appel reaction: total synthesis of the furan fatty acid $\mathbf{F}_{\mathbf{5}}$}

Received 00th January 20xx, Accepted 00th January 20xx

\author{
Robert J. Lee, ${ }^{a}$ Martin R. Lindley, ${ }^{b}$ Gareth J. Pritchard ${ }^{a *}$ and Marc C. Kimber ${ }^{a *}$
}

DOI: $10.1039 / \times 0 \times x 00000 x$

www.rsc.org/

Appel reaction conditions have been harnessed to affect a mild biosynthetically inspired dehydration of endoperoxides to deliver multi-substituted electron rich furans. Unlike traditional dehydrative procedures, this method is metal and acid free, and can be achieved under redox neutral conditions. It is general for a range of aryl and alkyl substituted endoperoxides, and is functional group tolerant. Furthermore, this procedure has been used to deliver an effective total synthesis of the furan fatty acid (FFA) $F_{5}$.

The Furan Fatty Acids (FFAs) are a sizeable class of natural products and metabolites that have shown to be protective toward the development of a number of chronic inflammatory diseases in humans (scheme $1(\mathbf{a}) ; \mathbf{1 a - h}){ }^{1}$

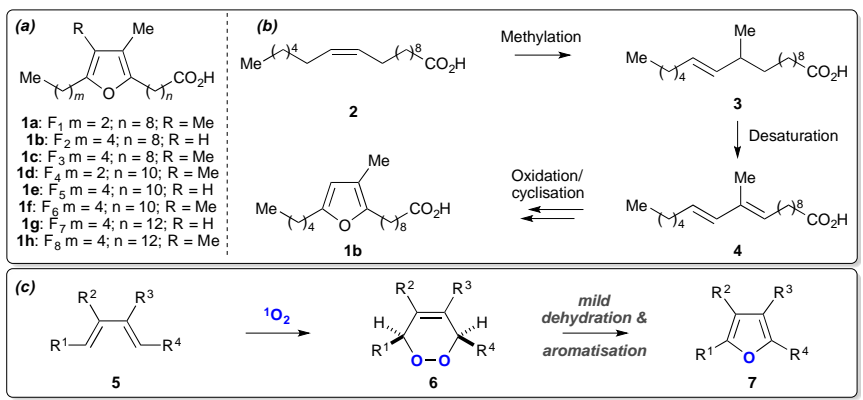

Scheme 1. (a) The eight most common FFAs, $F_{1-8}$; (b) The proposed biosynthetic pathway of FFAs; (c) Plausible route to FFAs.

FFAs are characterised by either a tri- or tetra-substituted furan; at the 2-position a $\mathrm{C}_{9}, \mathrm{C}_{11}$, or $\mathrm{C}_{13}$ alkyl chain terminates with a carboxyl functionality; at the 5-position, a straight chain propyl- or pentyl-chain is present, the former forming an

\footnotetext{
a. School of Science, Department of Chemistry, Loughborough University, Loughborough, LE11 3TU, UK Address here.

Email:M.C.Kimber@lboro.ac.uk; G.J.Pritchard@lboro.ac.uk

b. School of Sports, Exercise and Health Science, Loughborough University, Loughborough, LE11 3TU, UK

Electronic Supplementary Information (ESI) available: Detailed experimenta procedures and characterisation dtat for new compounds. See DOI: $10.1039 / x 0 \times x 00000 x$
}

interesting, and rarely seen, group of fatty acids which may be classified as omega-4; the 3-position of the furan ring is methylated across all FFAs reported to date; and finally, the 4position bears either a hydrogen atom or an additional methyl group. FFAs have been isolated from both marine ${ }^{2}$ and terrestrial plant origins, ${ }^{3}$ however the former were shown ultimately to derive from ingested algae. ${ }^{4}$ The protective abilities of FFAs are thought to derive from the electron-rich multi-substituted heterocyclic furanyl core, ${ }^{1 a}$ as it has been shown as a potent radical scavenger, which ultimately lends to their antioxidant qualities. ${ }^{1 \mathrm{~b}}$

Previous total syntheses of FFAs have seen the use of regioselective palladium mediated couplings on halogenated furans, and the selective modification of existing furan nuclei via functional group inter-conversions. ${ }^{5}$ Alternatively, the heterocyclic nucleus has been constructed by means of $\mathrm{Hg}$ (II) mediated rearrangement of appropriately substituted $\alpha$ hydroxy- $\beta$-alkynyl epoxides, ${ }^{6}$ acid catalysed rearrangement of bis-epoxides, ${ }^{7}$ or by the treatment of alkynediols with $\mathrm{Ag}(\mathrm{I})$ or iodine to effect cyclisation to the heterocycle. ${ }^{8}$ In contrast, synthetic methods that deliver FFAs via plausible biosynthetic routes are distinctly absent within the chemical literature. For example, the proposed biosynthetic route that delivers FFAs in marine bacteria ${ }^{9}$ is thought to proceed via a sequential oxidation/cyclisation pathway of 1,3-dienes (4, scheme $1(b)$ ) which are themselves produced by the enzymatic methylation and desaturation of bioavailable monounsaturated fatty acids such as cis-vaccenic acid; the bis-methyl FFAs are postulated to be the result of a further methylation step after construction of the heterocyclic nucleus.

A potent method for the incorporation of oxygen into organic substrates is the use of singlet oxygen $\left({ }^{1} \mathrm{O}_{2}\right)$, either via a cycloaddition event $([4+2]$ or $[2+2])$ or ene-type reaction. ${ }^{10}$ In the context of the proposed biosynthesis of FFAs in scheme $1,{ }^{1} \mathrm{O}_{2}$ could plausibly be used as a mimic for the conversion of $\mathbf{5}$ to $\mathbf{7}$, via a subsequent dehydrative cyclisation (scheme $1(\mathrm{c})$ ). The direct conversion of endoperoxides (8) to furans (11) can be grouped into (i) homolytic and (ii) heterolytic processes, both involving cleavage of the peroxide bond (scheme 2(a)). 
Homolytic processes typically employ transition metals (e.g. $\left.\mathrm{Ru}(\mathrm{II}),{ }^{11} \mathrm{Co}(\mathrm{II}),{ }^{12} \mathrm{Pd}(\mathrm{II}),{ }^{13} \mathrm{Sn}(\mathrm{II}),{ }^{14}\right)$ to mediate the transformation, however examples of thermal homolysis do exist. ${ }^{15}$ Indeed, the tetraphenylporphyrin Co(II) (CoTPP) catalysed method developed by Foote and co-workers was postulated to be a plausible biosynthetic mimic, that circumvented some of the harsher one-pot methods; however, the substrate scope within this disclosure was narrow, and the use of Co(II) can, in some cases, be complicated by the formation of bis-epoxide side-products. ${ }^{16}$ Heterolytic cleavage of the peroxide bond can be accomplished in a two-step process via a Kornblum DeLaMare (KDM) rearrangement, ${ }^{17}$ with the resultant cis- $\gamma$-hydroxyenone $(9)^{16}$ undergoing dehydration. ${ }^{18}$ Direct conversion to the furan under acidic conditions ${ }^{19}$ can also be performed with $\mathrm{TsCl}^{20}$ and $\mathrm{FeSO}_{4},{ }^{21}$ however the substrate scope is limited and may potentially be incompatible with electron rich furan products such as the FFAs.

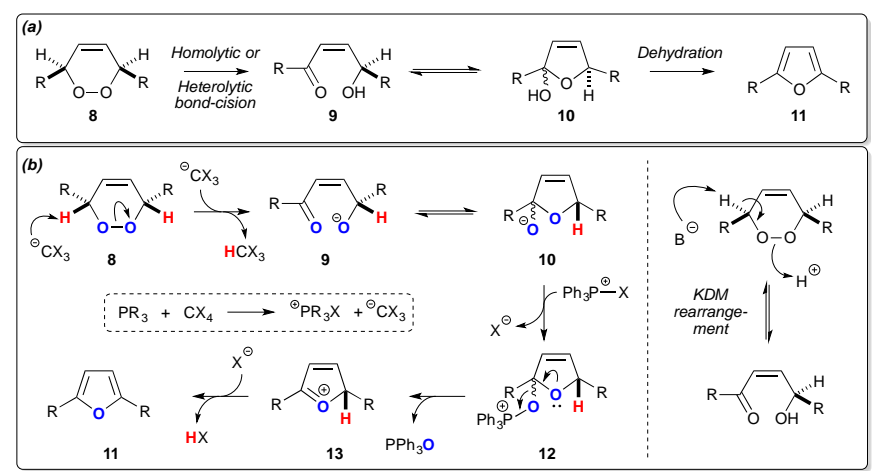

Scheme 2. (a) Conversion of endoperoxides to furans; (b) Appel-typ dehydration of endoperoxides to furans. $\mathrm{KDM}=$ Kornblum DeLaMare rearrangement.

In this communication we would like to report a new, biosynthetically inspired method for the preparation of electron rich multi-substituted furan nuclei, which is general for a variety of endoperoxides. To achieve this we have employed Appel-type conditions, commonly applied in the mild, redox neutral synthesis of alkyl halides from alcohols. ${ }^{22}$ The initial hypothesis for using the Appel reaction is outlined in scheme 2(b). Mirroring the Appel reaction, we hoped the $\mathrm{CX}_{3}$ carbanion, generated from $\mathrm{PR}_{3}$ and $\mathrm{CX}_{4}$, would be suitably basic to promote the KDM rearrangement giving enone $9.16,17$ This enone will be in equilibrium with the cyclic form 10, with this latter intermediate undergoing a subsequent dehydration via the expulsion of $\mathrm{Ph}_{3} \mathrm{PO}$ to deliver the desired furan $\mathbf{1 1}$.

Our initial work focused on the dehydration of endoperoxide 14a, obtained by the addition of singlet oxygen to commercially available trans, trans-1,4-diphenylbutadiene (table 1). We discovered that the treatment of $14 a$ with 1.1 equivalents of $\mathrm{PPh}_{3}$ and 1.1 equivalents of $\mathrm{CBr}_{4}$ in dichloromethane led to a moderate yield of the desired furan 15a after $16 \mathrm{~h}$ (table 1, entry 1 ). Encouraged by this we carried out a small optimisation study, focusing on temperature and the stoichiometry of $\mathrm{PPh}_{3}$ and $\mathrm{CBr}_{4}$. Repeating the reaction at RT with freshly sublimed $\mathrm{CBr}_{4}$ led to dramatic increase in conversion, and we were able to isolate 15 a in $85 \%$ yield (entry
2). A variation in the temperature of the reaction indicated that a reaction window between $10-20^{\circ} \mathrm{C}$ was optimal (entries 3 and 4), while undertaking the reaction in the absence of either $\mathrm{PPh}_{3}$ (entry 5) or $\mathrm{CBr}_{4}$ (entry 6) showed no conversion to the furan and recovery of 14a. A switch to THF was shown to be detrimental to the reaction giving the furan in only $58 \%$ conversion, and moreover, the reaction was distinctly less clean under these conditions (entry 7).

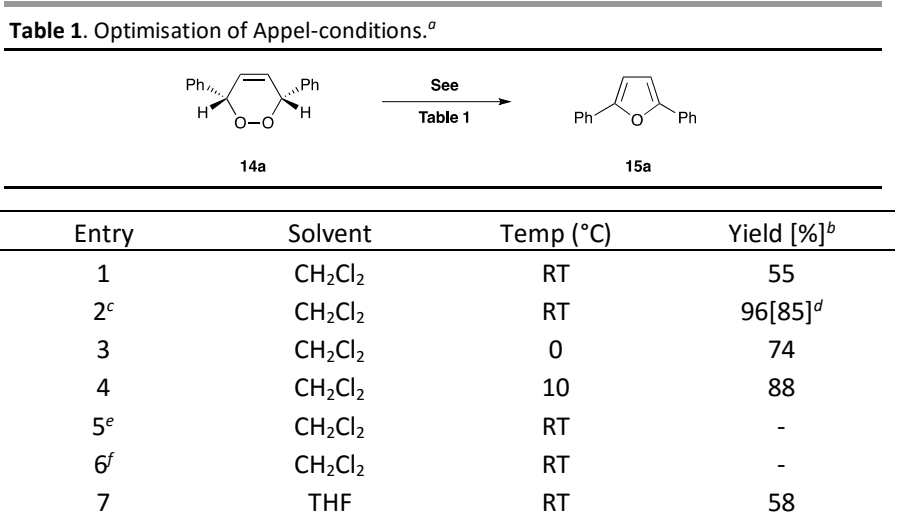

${ }^{a}$ Conditions: 14a (0.1 mmol), $\mathrm{CBr}_{4}$ (1.1 equiv), $\mathrm{PPh}_{3}$ (1.1 equiv), $\mathrm{CH}_{2} \mathrm{Cl}_{2}, \mathrm{RT}, 0.1 \mathrm{M}$, $16 \mathrm{~h}$, unless stated otherwise. ${ }^{b}$ Conversion calculated by ${ }^{1} \mathrm{H}$ NMR using $1,3,5-$ trimethoxybenzene as an internal standard. ${ }^{c}$ Freshly sublimed $\mathrm{CBr}_{4}$. ${ }^{d}$ Isolated chemical yields. ${ }^{e} \mathrm{No} \mathrm{PPh}_{3} .{ }^{f} \mathrm{No} \mathrm{CBr}_{4}$.

With effective conditions to hand, we progressed to expanding the endoperoxide substrate scope (table 2). The endoperoxides $(\mathbf{1 4} \mathbf{b}-\mathbf{m})$ were prepared by the treatment of the corresponding 1,3-dienes with oxygen with a suitable photosensitizer. ${ }^{23}$ Endoperoxides $\mathbf{1 4 b}$-d all dehydrated to give the required furans $\mathbf{1 5 b}-\mathbf{d}$ in high chemical yield (entries 1-3). Endoperoxides $\mathbf{1 4 e}$ and $\mathbf{1 4 f}$, which were both isolated as a mixtures of diastereomers in the preceding photo-oxidation as a consequence of the 1,3-dienes, smoothly dehydrated to give the furans $\mathbf{1 5 e}$ and $\mathbf{1 5 f}$ in $76 \%$ and $50 \%$ yield, respectively (entries 4 and 5). The process was also tolerant of a preinstalled cyclopropyl motif within the endoperoxide $\mathbf{1 4 g}$, giving the tri-substituted furan $\mathbf{1 5 g}$ in $93 \%$ yield (entry 6). Endoperoxides $14 \mathrm{~h}, \mathrm{i}$ have pre-installed functionality on the alkyl chain at the $\mathrm{C} 3, \mathrm{C} 6$ positions, and both cleanly gave their individual furans $(\mathbf{1 5 h}, \mathbf{i})$ in high yield (entries 7 and 8). Endoperoxide $\mathbf{1 4} \mathbf{j}$, containing a OTBS group, neatly transformed into the furan $\mathbf{1 5 j}$ in $63 \%$ yields; however trace amounts of a furan, identified as the bromide 15j', were observed as a by-product of this reaction (entry 9). This product was postulated to arise from an in situ deprotection of the OTBS, followed by conversion of the primary alcohol to the bromide under the Appel conditions. However, access to bromide 15j' was perceived to be advantageous, as it could be utilised in subsequent cross-coupling reactions or direct conversion to the carboxylic acids. Therefore, to increase its yield, we exposed 14j to 2.2 equiv of $\mathrm{CBr}_{4}$ and $\mathrm{PPh}_{3}$, respectively, and this gave $\mathbf{1 5 j}$ ' in an excellent isolated yield of 91\% (entry 10). Endoperoxides 14k-m contain a pentyl side chain common to the FFAs $F_{2,3}$ and $F_{5-8}$, and all could be efficiently converted to their furan derivatives (15k-m) using 
the Appel protocol, and importantly, $\mathbf{1 5 m}$ contains functional groups that can be potentially further functionalised (entry 1113). Finally, 14a was dehydrated on a $5.0 \mathrm{mmol}$ scale to give the furan 15a in very high chemical yield (entry 14).

Table 2. Substrate scope for the preparation of multi-substituted furans. ${ }^{a}$

\begin{tabular}{|c|c|c|c|}
\hline Entry & Endoperoxide & Furan & Yield $^{b}$ \\
\hline 1 & & & 82 \\
\hline 2 & $14 \mathrm{c}$ & & 91 \\
\hline 3 & $14 d$ & $15 d$ & 87 \\
\hline 4 & $14 e$ & $15 \mathrm{e}$ & 76 \\
\hline 5 & $14 f$ & $15 f$ & 50 \\
\hline 6 & $14 \mathrm{~g}$ & $15 \mathrm{~g}$ & 93 \\
\hline 7 & $14 \mathrm{~h}$ & $15 \mathrm{~h}$ & 98 \\
\hline 8 & $14 \mathrm{i}$ & $15 i$ & 94 \\
\hline 9 & & $15 \mathrm{j}$ & 63 \\
\hline $10^{c}$ & $14 \mathrm{j}$ & $15 j^{\prime}$ & 91 \\
\hline 11 & $14 k$ & $15 \mathrm{k}$ & 83 \\
\hline 12 & 141 & 151 & 72 \\
\hline 13 & $14 \mathrm{~m}$ & $15 \mathrm{~m}$ & 54 \\
\hline $14^{d}$ & $14 a$ & $15 a$ & 95 \\
\hline
\end{tabular}

${ }^{a}$ Conditions, endoperoxide (0.1 to $1.1 \mathrm{mmol}$ ), $\mathrm{CBr}_{4}$ (1.1 equiv), $\mathrm{PPh}_{3}$ (1.1 equiv), $\mathrm{CH}_{2} \mathrm{Cl}_{2}, \mathrm{RT}, 0.1 \mathrm{M}$ unless otherwise stated. ${ }^{b}$ Isolated yields. ${ }^{\circ} \mathrm{CBr}_{4}$ (2.2 equiv), $\mathrm{PPh}$ (2.2 equiv) at reflux. ${ }^{d}$ Undertaken with $5.0 \mathrm{mmol}$ of 14 a.

The proposed biomimetic synthesis of tetra-substituted FFAs necessitates the introduction of the final methyl group on the furan ring after its formation. This proposition is partially supported by the performance of a tetra-substituted 1,3-diene under our photo-oxidation conditions. We observed that tetrasubstituted 1,3-diene 16, did not give the expected endoperoxide 17, but gave predominantly an over-oxidised product 18 in $86 \%$ isolated yield (scheme 3 ). The reaction outcome was the same whether undertaken with Rose Bengal or Methylene Blue as the photo-sensitizer. This product presumably results from an initial [4+2]-cycloaddition event on 16 giving 17, followed by a subsequent ene-reaction on the electron rich alkene of $\mathbf{1 7}$ to ultimately furnish $\mathbf{1 8}$. However, while initially discouraging, this reaction manifold does give rapid access to structures such as $\mathbf{1 8}$ that are reminiscent of the important antimalarial artemisinin. ${ }^{24,25}$

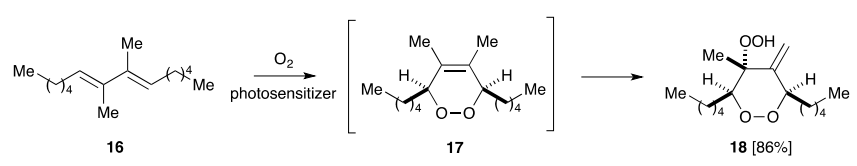

Scheme 3. Photo-oxidation of tetra-substituted 1,3-diene 18.

Finally, to demonstrate the applicability of this dehydrative process we targeted the synthesis of the FFA $F_{5}$ methyl ester (scheme 4). The synthesis began with conversion of the alcohol 19 to its phosphonium salt 21 under standard conditions, with $\mathbf{2 1}$ undergoing olefination with ketone $\mathbf{2 2}$, giving triene $\mathbf{2 3}$ as a mixture of $E / Z$ isomers in a ratio of $1: 2.2$. Selective [4+2]cycloaddition of $\mathbf{2 3}$ with singlet oxygen initially proved problematic; however a change in solvent and the photosensitizer yielded the required endoperoxide $\mathbf{2 4}$ in an isolated yield of $49 \%$. With 24 in hand, dehydration under our conditions proved successful and we were able to deliver the desired furan $\mathbf{2 5}$ in $66 \%$ yield, but importantly with a terminal alkene within the side chain. Previous work by Knight and coworkers $^{8 c}$ has established that the furan heterocycle is compatible with cross-metathesis conditions; therefore, exposure of $\mathbf{2 5}$ to methyl acrylate under mild cross-metathesis conditions, followed by introduction of catalytic $\mathrm{PtO}_{2}$ under a hydrogen atmosphere gave the desired $F_{5}$ methyl ester (1e) in near quantitative yield over these two-steps.

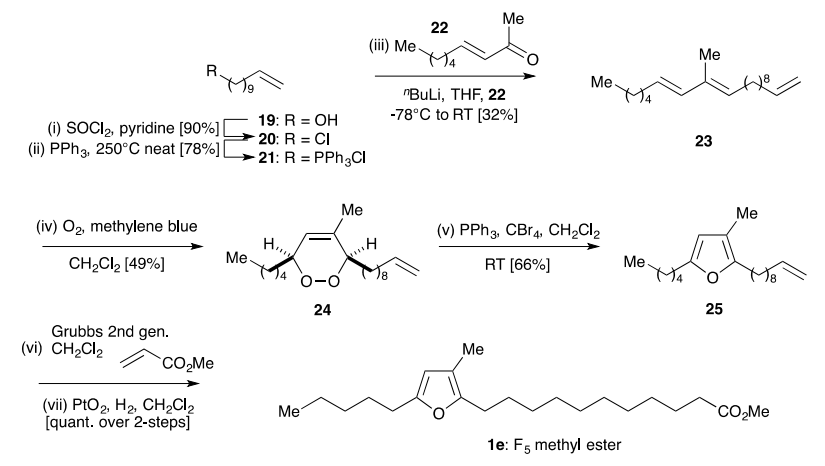

Scheme 4. Total synthesis of the methyl ester of the furan fatty acid $F_{5}$

In conclusion, we have developed a unique application of the Appel reaction to effect the transformation of endoperoxides to furans, without the involvement of a transition metal or strong acid. This approach is functional group tolerant and amenable to target synthesis as demonstrated by the successful construction of the methyl ester derivative of the furan fatty acid $F_{5}$, in only 7-steps from a commercially available alcohol. Optimisation of the biosynthetic oxidation pathway, for the formation of the 
endoperoxide intermediate, to suppress the formation of overoxidation products, as well as total synthesis and biological evaluation of all the $F$ acids is currently underway. Additionally, to complement the DoE solvent evaluation, we are also currently investigating whether this process can be achieved under catalytic Appel conditions and under continuous flow conditions. ${ }^{26}$

We thank Loughborough University for financial support (RJL). Additionally, Matthew Turner (Loughborough) for MS analysis; Dr. Mark Edgar (Loughborough) for NMR structure determination; and John Spray (Loughborough) for our small scale photo-reactor design build

\section{Notes and references}

1 (a) G. Spiteller, Lipids 2005, 40, 755; (b) G. Spiteller, Mol. Biotechnol. 2007, 37, 5.

2 R. L. Glass, T. P. Krick, D. M. Sand, C. H. Rahn and H. Schlenk, Lipids 1975, 10, 695.

3 K. Hannemann, V. Puchta, E. Simon, H. Ziegler, G. Ziegler and G. Spiteller, Lipids 1989, 24, 296.

4 A. Batna, J. Scheeinkonig and G. Spiteller, Biochim. Biophys. Acta 1993, 1166, 171.

5 (a) C. H. Rahm, D. M. Sand, Y. Wedmid and H. Schlenk, J. Org Chem. 1979, 44, 3420; (b) R. Schödel and G. Spiteller, Helv. Chim. Acta 1985, 68, 1624; (c) T. Bach and L. Krüger Tetrahedron Lett. 1998, 39, 1729; (d) T. Bach and L. Krüger, Eur. J. Org. Chem. 1999, 2045.

6 (a) C. M. Marson and S. Harper, Tetrahedron Lett. 1998, 39 333; (b) C. M. Marson and S. Harper, J. Org. Chem. 1998, 63 9223.

7 G. B. Bantchev, K. M. Doll, G. Biresaw and K. E. Vermillion, J. Am. Oil Chem. Soc. 2014, 91, 2117.

8 (a) A. B. Evans, S. Flügge, S. Jones, D. W. Knight and W. $-T$ Tan, Arkivoc 2008, 10, 95; (b) S. P. Bew, G. M. M. El-Taeb, S. Jones, D. W. Knight and W. -T. Tan, Eur. J. Org. Chem. 2007, 5759; (c) D. W. Knight and A. W. T. Smith, Tetrahedron 2015 71, 7436; (d) D. W. Knight and A. W. T. Smith, Heterocycles $2012,84,361$.

9 N. Shirasaka, K. Nishi and S. Shimizu, Biochem. Biophys. Acta 1997, 1346, 253.

10 For reviews on the synthetic utility of endoperoxides see (a) M. Balci, Chem, Rev. 1981, 81, 91; (b) E. L. Clennan, Tetrahedron 1991, 47, 1343; (c) A. A. Ghogare and A. Greer, Chem. Rev. 2016, 116, 9994; for a review on the complex relationship of furans with ${ }^{1} \mathrm{O}_{2}$ see (d) T. Montagnon, D. Kalaitzakis, M. Triantafyllakis, M. Stratakis and G. Vassilikogiannakis, Chem. Commun. 2014, 50, 15480.

11 M. Suzuki, H. Ohtake, Y. Kameya, N. Hamanaka and R. Noyori, J. Org. Chem. 1989, 54, 5292.

12 (a) K. E. O'Shea and C. S. Foote, J. Org. Chem. 1989, 54, 3475; (b) R. Ozen, F. Kormali, M. Balci and B. Atasoy, Tetrahedron 2001, 57, 7529; (c) B. Atasoy and R. Özen, Tetrahedron 1997, 53, 13867.
13 M. Suzuki, Y. Oda, N. Hamanaka and R. Noyori, Heterocycles 1990, 30, 517.

14 S. Kohmoto, S. Kasai, M. Yamamoto and K. Yamada, Chem. Lett. 1998, 9, 1477.

15 (a) J. A. Celaje, D. Zhang, A. M. Guerrero and M. Selke, Org. Lett. 2011, 13, 4846; (b) M. Campagnole and M. -J. Bougeois, Tetrahedron 2002, 58, 1165.

16 (a) M. C. Kimber and D. K. Taylor, In Trends in Organic Chemistry 2001, 9, 53; (b) I. A. Yaremenko, V. A. Vil', D. V. Demchuk and A. O. Terent'ev, Beilstein J. Org. Chem. 2016, 12, 1647;

17 (a) N. Kornblum and H. De La Mare, J. Am. Chem. Soc. 1951 73, 881; for examples of the KDM rearrangement in target synthesis see (b) C. F. Hugelshofer and T. Magauer, J. Am. Chem. Soc. 2015, 137, 3807; (c) J. Priest, M. R. Longland, M. R. J. Elesgood and M. C. Kimber, J. Org. Chem. 2013, 54, 4098; (d) M. J. Palframan, G. Kociok-Köhn and S. E. Lewis, Chem. Eur. J. 2012, 18, 4766; (e) K. C. Nicolaou, S. Totokotsopoulos, D. Giguere, Y. Sun and D. Sarlah, J. Am. Chem. Soc. 2011, 133, 8150.

18 (a) V. V. Mahindroo, V. Singh and S. Dev, Indian J. Chem., Sect $B$ 1998, 278, 1080; (b) K. Kondo and M. Matsumoto, Tetrahedron Lett. 1976, 48, 4363; (c) K. Ono, M. Nakagawa and A. Nishida, Angew. Chem. Int. Ed. 2004, 43, 2020; (d) A. G. Griesbeck, A. de Kiff and M. Kleezka, Adv. Synth. Catal. 2014, 356, 2839; (e) N. Saito, K. Saito, M. Shiro and Y. Sato, Org. Lett. 2011, 13, 2718; (f) A. Eske, B. Goldfus, A. G. Griesbeck, A. de Kiff, M. Kleczka, M. Leven, J. -M.; Neudörfl and M. Vollmer, J. Org. Chem. 2014, 79, 1818.

19 C. E. Hewton, M. C. Kimber and D. K. Taylor, Tetrahedron Lett. 2002, 43, 3199.

20 B. Harirchian and B. B. Magnus, Synth. Commun. 1977, 7, 119.

21 (a) P. F. Vlad, A. Ciocarlan, C. Edu, A. Aricu, A. Biriiac, M. Colsta, M. D'Ambrosio, C. Deleanu, A. Nicolescu, S. Shova, N. Vornicu and A. de Groot, Tetrahedron 2013, 69, 918; (b) Y. K. Yang, J. -H. Choi and J. Tae, J. Org. Chem. 2005, 70, 6995; (c) R. -R. Juo and W. Herz, J. Org. Chem. 1985, 50, 700; (d) R. -R. Juo and W. Herz, J. Org. Chem. 1985, 50, 618.

22 (a) R. Appel, Angew. Chem. Int. Ed. 1975, 14, 801; (b) V. S. C. De Andrade and M. C. S de Mattos, Curr. Org. Synth. 2015, $12,309$.

23 See the Supporting Information for their preparation and characterization.

24 D. Chaturvedi, A. Goswami, P. P. Saikia, N. C. Barau and P. G. Rao, Chem. Soc. Rev. 2010, 39, 435.

25 The oxidation of hexamethylbenzene gives a related product see (a) C. J. M. Van den Heuvel, H. Steinberg and T. J. De Boer, Recl. Trav. Chim. Pays-Bas. 1977, 6, 157; (b) C. Y. Park, J. H. Park, H. J. Lim, G. -S. Hwang and C. P. Park, Bull. Korean Chem. Soc. 2014, 35, 983.

26 For the catalytic Appel reaction and related nucleophilic substitution reactions see (a) H. A. van Kalheran, F. L. van Delft and F. P. J. T. Rytjesm, Pure Appl. Chem. 2013, 85, 817; (b) J. An, R. M. Denton, T. H. Lambert and E. D. Nacsa, Org. Biomol. Chem. 2014, 12, 2993. 